\title{
Assessment of Learning Preferences and Outcomes Among Dental and Allied Health Science Students: A Multi-Institutional Study
}

\section{Archana Krishna Murthy ${ }^{1}$, Shilpashree $\mathrm{KB}^{2}$, Shahina Yasmin ${ }^{3 *}$ and Mumin Rashid ${ }^{3}$}

${ }^{1}$ Head and Professor, Department of Public Health Dentistry, The Oxford Dental

College, Bengaluru, India

${ }^{2}$ Professor, Department of Public Health Dentistry, The Oxford Dental College,

Bengaluru, India

${ }^{3}$ Postgraduates, Department of Public Health Dentistry, The Oxford Dental College,

Bengaluru, India

* Corresponding Author: Shahina Yasmin, Postgraduates, Department of Public

Health Dentistry, The Oxford Dental College, Bengaluru, India.
Received: October 07, 2021

Published: December 23, 2021

(C) All rights are reserved by Shahina Yasmin., et al.

\section{Abstract}

Aim: To assess learning preferences and outcomes among dental and allied health science students.

Objectives: The present study was conducted with the objectives and to assess learning preferences using Visual, Aural, Read/Write, and Kinesthetic Questionnaire and to assess students learning outcomes using student's yearly performance.

Material and Methods: A cross-sectional study was conducted among the final year students from nursing, pharmacy, physiotherapy and dental colleges of The Oxford group of institution. VARK (Version 7.8) questionnaire was administered to the study population to collect information regarding participants' learning preferences and the individual's learning outcomes was collected by collecting yearly performance from the heads of the institution of each of the college.

Results: A total of 278 final year students were recruited from the four different institutions of Oxford which included 81 nursing students,54 physiotherapy,74 pharmacy students and 69 dental students. The mean age of the study participant was found to be 23.1 \pm 1.04 years of which $36.3 \%$ of the study participants were males and $63.7 \%$ were females. In the present study the most preferred learning style was visual (70\%), followed by kinesthetic (69.4\%) and aural (68\%) and the least preferred was reading style (46\%). When the modality of learning among students was taken into consideration, in the present study, about half of the study participants had preference for bimodal (54.7\%) style of learning followed by unimodal (26.3\%), trimodal (18.3\%) and least chosen modality was quad modal $(0.7 \%)$. When the performance of the students was taken into account, in the present study no significant difference was found between the learning styles $(p=0.09)$ and academic performance, however significant difference ( $p=0.01)$ was found between academic performance and the modality used in learning.

Conclusion: The present educational system focuses mainly on the ways in which students are being taught. The questionnaires of VARK can be extensively used by researchers to analyse learning style preferences as it is essential for a teacher to recognise that students have different styles of learning. This recognition will aid them to consider selecting different modalities and preferences, and reflect on the instruction modes effectiveness.

Keywords: Learning Preferences; VARK; Learning Outcomes; Learning Styles; Students 


\section{Abbreviation}

VARK: Visual, Aural, Read/Write, and Kinesthetic

\section{Introduction}

Learning style is an individual's characteristic method of gaining knowledge, skills, and attitudes through study or experiences [1]. Among the different models that have been proposed, the visual, aural, read/write, and kinesthetic (VARK) model developed by Neil Fleming is one of the most frequently used methods, and describes preferences in terms of 4 types of preferred learning styles (visual, aural, read/write, and kinesthetic) [2]. The characteristics of university learners are very varied in terms of age, culture, level of mentality preparedness, intelligence and psychological conditions, which lead to differences in individual learning styles in sensory modalities. Students basically use different approaches to obtain required information, as their learning is affected by learning atmosphere and curricular issues, as well as teaching methods. Therefore, it seems that teaching methods have to be organized individually, according to their individual characteristics. Learning style is a complicated approach in which the learner should save, recall and process the concepts efficiently and effectively. Visual, aural, reading and writing and kinesthetic (VARK) is one of the instruments which can be used to determine the learning styles. ${ }^{3}$ Therefore, the aim of the present study is to investigate the preferred learning preferences and learning outcomes among the dental and health science students.

\section{Material and Methods}

A cross-sectional study was conducted for 3 months among the final year Students from nursing, pharmacy, physiotherapy and dental colleges of The Oxford Group of Institution. VARK (Version 7.8) questionnaire was administered to the study population to collect information regarding participants' learning preferences and the individual's learning outcomes was collected by collecting the students' previous year's performance from the heads of the institution of each of the colleges. Inclusion criteria comprised of (i) Subjects willing to participate (ii) Subjects who were able to speak/ read English. Exclusion criteria comprised of (i) Subjects not willing to participate. (ii) Subjects not present on the day of the data collection.

Ethical Clearance was obtained from the Institutional Review Board of The Oxford Dental College, Bengaluru. Further the per- mission to conduct the study was taken from the principal of The Oxford Dental College, and head of the institution of the respective colleges.

The study participants were explained in detail about the study. On agreeing to participate in the study on the day of study, the participant conducted were distributed consent form where an informed consent was obtained.

The questionnaire was distributed to all the students present on the day of the study. The learning preferences of individual students was collected using self-administered questionnaire (VARK: Version 7.8) and then students were categorized into different models depending upon the total scores obtained for V, A, R and $\mathrm{K}$ respectively. The students were categorized into first class, second class, distinction based on their annual performance which was statistically analysed using chi square test. The data analysis included descriptive statistics using the Chi-square test and t-test. Statistical analysis was done using SPSS. Quantitative data was evaluated using independent $t$ tests in order to compare the two groups and p-value $\leq 0.05$ was considered significant.

\section{Results}

A total of 278 final year students were recruited from the four different institution of Oxford which included 81 nursing students, 54 physiotherapy,74 pharmacy students and 69 dental students. The mean age of the study participant was found to be $23.1 \pm 1.04$ years of which $36.3 \%$ of the study participants were males and $63.7 \%$ were females.

Distribution of study participants based on their learning modes is represented graphically in figure 1 . The most preferred learning mode among the nursing, physiotherapy and dental students was kinesthetic $(56.8 \%),(109.3 \%)$ and $66.7 \%$ respectively whereas among the pharmacy students the preferred learning mode was visual (98.1\%). Further the least chosen learning mode among all the four groups was reading mode that is $47 \%$ (Nursing), 46.3\% (Physiotherapy), 74\% (Pharmacy) and 36.2\% (dental) and the difference in learning mode between the groups was found to be statically not significant $(\mathrm{p}=0.31)$.

Table 2 shows the distribution of study participants based on learning models. When distribution of study participants based on learning models was taken into consideration, it was seen that the 


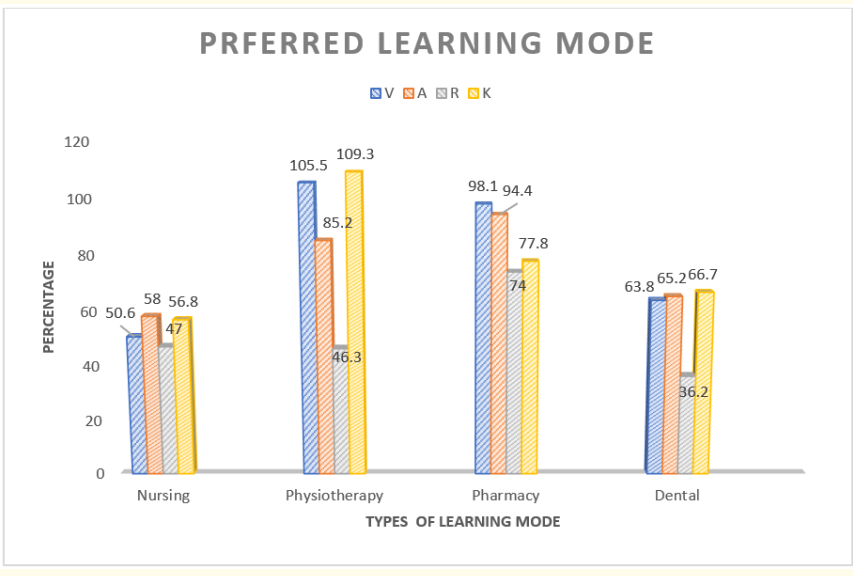

Figure 1: Distribution of study participants based on their preference for learning modes.P: Piroxicam and Group A: Articaine).

most preferred learning model among the nursing and physiotherapy was bimodal (65.4\%), (55.4\%) respectively whereas among pharmacy and dental students the preferred learning mode was unimodal (66.6\%) and trimodal (52.2\% respectively). The difference in the learning model between the groups was found to be statistically highly significant $\left(\mathrm{p}=0.01^{*}\right)$.

When academic performance among nursing students was taken into consideration, it was seen that the nursing students in unimodal belonged more to second class (69.2\%) than in first class $(23.1 \%)$ or distinction $(7.7 \%)$ and the difference in the academic performance among the three groups was found to be statistically significant $\left(\mathrm{p}=0.01^{*}\right.$ ). Further, when academic performance among physiotherapy was taken into consideration, it was seen that the students in unimodal belonged more to second class (69.2\%) than in first class $(23.1 \%)$ or distinction $(7.7 \%)$ and the difference in the academic performance among the three groups was found to be statistically significant $\left(\mathrm{p}=0.03^{*}\right)$.Similarly, students in the bimodal group secured second class (49\%) more effectively than first class (45.3\%) or distinction (5.7\%) and the difference was found to be statistically significant $\left(\mathrm{p}=0.03^{*}\right)$.

Moreover, when academic performance among pharmacy was taken into consideration, it was seen that the students in unimodal belonged more to second class (52.8\%) than in first class (41.6\%) or distinction (5.6\%) and the difference in the academic performance among the three groups was found to be statistically significant $\left(\mathrm{p}=0.011^{*}\right)$.Similarly, students in the bimodal group secured second class (18.4\%) more effectively than first class $(52.6 \%)$ or distinction $(7.8 \%)$ and the difference was found to be statistically significant $\left(\mathrm{p}=0.011^{*}\right)$.

Furthermore, among dental students, when academic performance was evaluated, it was seen that the students in unimodal belonged more to first class (63.6\%) than in second class $(36.4 \%)$ and none secured distinction (0\%) and the difference in the academic performance among the three groups was found to be statistically significant $\left(\mathrm{p}=0.017^{*}\right)$.Further, the students in bimodal secured first class whereas students in first class (0\%) and distinction $(0 \%)$ did not use bimodal at all. Similarly, students in the trimodal group secured second class (51.4\%) more effectively than first class $(37.8 \%)$ or distinction $(10.8 \%)$ and the difference was found to be statistically significant $\left(\mathrm{p}=0.017^{*}\right)$.

\begin{tabular}{|c|c|c|c|c|c|c|}
\hline Group & Unimodal & Bimodal & Trimodal & Quadmodal & Total & p-Value \\
\cline { 1 - 5 } $\begin{array}{c}\text { Nursing } \\
\text { N = 81 }\end{array}$ & $13(16.1)$ & $53(65.4)$ & $15(18.5)$ & $0(0)$ & $81(100)$ & $\mathrm{p}=0.01^{*}$ \\
\cline { 1 - 5 } $\begin{array}{c}\text { Physiotherapy } \\
\text { N = 54 }\end{array}$ & $13(17.6)$ & $41(55.4)$ & $20(27)$ & $0(0)$ & $74(100)$ & \\
\cline { 1 - 5 } $\begin{array}{c}\text { Pharmacy } \\
\text { N = 74 }\end{array}$ & $36(66.6)$ & $38(51.4)$ & $0(0)$ & $0(0)$ & $54(100)$ & \\
\cline { 1 - 4 } Dental \\
N =69 & $11(16)$ & $20(29)$ & $36(52.2)$ & $2(2.8)$ & $69(100)$ & \\
\cline { 1 - 4 } TOTAL & $73(26.3)$ & $152(54.7)$ & $51(18.3)$ & $2(0.7)$ & $278(100)$ & \\
\hline
\end{tabular}

Table 1: Distribution of study participants based on their preference for learning models. 


\begin{tabular}{|c|c|c|c|c|c|c|}
\hline Course & Model type & Second class & First class & Distinction & Total & p-VALUE \\
\hline \multirow[t]{5}{*}{ Nursing } & Unimodal & 9 (69.2) & $3(23.1)$ & $1(7.7)$ & $13(16.1)$ & \multirow[t]{5}{*}{$\mathrm{p}=0.01^{*}$} \\
\hline & Bimodal & $26(49)$ & $24(45.3)$ & $3(5.7)$ & $53(65.4)$ & \\
\hline & Trimodal & $0(0)$ & $15(100)$ & $0(0)$ & $15(18.5)$ & \\
\hline & Quadmodal & $0(0)$ & $0(0)$ & $0(0)$ & $0(0)$ & \\
\hline & Total & $35(43.2)$ & $42(51.8)$ & $4(5)$ & 81 & \\
\hline \multirow{5}{*}{$\begin{array}{l}\text { Physiother- } \\
\text { apy }\end{array}$} & Unimodal & $2(15.4)$ & $9(69.2)$ & $2(15.4)$ & $13(24.1)$ & \multirow[t]{5}{*}{$\mathrm{p}=0.03^{*}$} \\
\hline & Bimodal & $28(68.2)$ & $9(22)$ & $4(9.8)$ & $41(75.9)$ & \\
\hline & Trimodal & $0(0)$ & $0(0)$ & $0(0)$ & $0(0)$ & \\
\hline & Quadmodal & $0(0)$ & $0(0)$ & $0(0)$ & $0(0)$ & \\
\hline & Total & $30(55.5)$ & $18(33.4)$ & $6(11.1)$ & $54(100)$ & \\
\hline \multirow[t]{5}{*}{ Pharmacy } & Unimodal & $15(41.6)$ & $19(52.8)$ & $2(5.6)$ & $36(48.6)$ & \multirow[t]{5}{*}{$\mathrm{p}=0.011^{*}$} \\
\hline & Bimodal & $7(18.4)$ & $28(52.6)$ & $3(7.8)$ & $38(51.4)$ & \\
\hline & Trimodal & $(0)$ & $0(0)$ & $(0)$ & $(0)$ & \\
\hline & Quadmodal & $(0)$ & $0(0)$ & $(0)$ & $(0)$ & \\
\hline & Total & $22(29.7)$ & $47(63.6)$ & $5(6.7)$ & $74(100)$ & \\
\hline \multirow[t]{5}{*}{ Dental } & Unimodal & $4(36.4)$ & $7(63.6)$ & $0(0)$ & $11(16)$ & \multirow[t]{5}{*}{$\mathrm{p}=0.017^{*}$} \\
\hline & Bimodal & $0(0)$ & $20(100)$ & $0(0)$ & $20(29)$ & \\
\hline & Trimodal & $19(51.4)$ & $14(37.8)$ & $3(10.8)$ & $36(52.2)$ & \\
\hline & Quadmodal & $2(100)$ & $0(0)$ & $0(0)$ & $2(2.8)$ & \\
\hline & Total & $25(36.2)$ & $41(59.4)$ & $3(4.4)$ & $69(100)$ & \\
\hline
\end{tabular}

Table 2: Distribution of study participants based on their preference for learning models and their academic performance.

$\mathrm{p}<0.05^{*}$ : Statistically significant

$\mathrm{p}<0.001^{* *}$ : Statistically highly significant.

\section{Discussion}

The unique learning preference of an individual, including the strategies used to interact with information, describes the individual's learning style. It has been argued that being aware of these differences in learning styles allows teachers to adjust their methods to better match the preferences of their students, which will increase learning effectiveness and efficiency. On the learner's side, identifying one's learning style preference may result in decisions that improve the outcomes of their learning in addition to increasing student satisfaction toward educational process.

Over the past four decades, numerous models have been developed to characterize learning style preferences in pedagogics. One of the more commonly used models to categorize instructional preferences is Neil Fleming's VARK model, which classifies the learning preferences based on the sensory pathways into four modes: visual (V), aural (A), read/write (R), and kinesthetic (K). $A$ visual $(V)$ learner prefers the use of charts, diagrams, and other forms of illustrative imaging to acquire information. An auditory (A) learner prefers the spoken word through lectures, podcasts, and oral discussions as the means of learning. The read/write (R) preference is when the acquisition of new information is done through the printed word via books and handouts, and tables and lists, and using writing to record and recall new information.

The present educational system focuses mainly on the ways in which students are being taught. The questionnaires of VARK are extensively used by researchers to analyse learning style preferences. It is essential for a teacher to recognise that students have different styles of learning. This recognition will aid them to con- 
sider selecting different modalities and preferences, and reflect on the instruction modes effectiveness.

In the present study, a total of 278 participants were recruited from four different colleges from The Oxford group of institutions which consisted of nursing, physiotherapy, pharmacy and physiotherapy students. The mean age was $23.1 \pm 1.04$ years among which $30 \%$ were males and $70 \%$ were females which was similar to the study conducted by Peyman., et al. [3] where $66 \%$ of the participants were females and 34\% were male participants. However, the findings of the present study are in contrast to the study conducted by Aldosari., et al. [4] which comprised of $73.1 \%$ male and $26.9 \%$ female participants. The high male participation in the study conducted by Aldosari., et al. [4] was due to the fact that there were separate campuses for male and female students and therefore there was a difference in scheduling of classes and exams that might have contributed to the disparity between male and female student participation in that particular study.

In the present study the most preferred learning style was visual (70\%), followed by kinesthetic $(69.4 \%)$ and aural $(68 \%)$ and the least preferred was reading style (46\%). However, no statistically significant difference was found in learning styles between the groups. The results of the present study were similar to the findings of the study conducted by Baykan Z [5] where the most preferred learning style was kinesthetic (23.3\%), followed by auditory $(7.7 \%)$, visual $(3.2 \%)$, and least preferred was reading style $(1.9 \%)$. Further the outcomes of the present study were inconsistent with the findings of the study conducted by Peyman H., et al. [3] where $17.7 \%$ preferred the Aural style, $17 \%$ preferred Reading and Writing, 6.4\% preferred Kinesthetic style and $0.7 \%$ preferred Visual styles. Also, the findings of the study conducted by Wong., et al. [6] was incompatible with the present study where the most common type of learners was the reading/writing type (27.30\%) whereas in the present study reading/writing type was the least chosen mode. This discrepancy in the learning preference among students may be attributed to the differences in the teaching methodologies as well as the difference in the personal learning preference among students.

When the modality of learning among students was taken into consideration, in the present study, about half of the study participants had preference for bimodal (54.7\%) style of learning followed by unimodal (26.3\%), trimodal (18.3\%) and least chosen modality was quad modal (0.7\%).The bimodal preference among the students was higher than the study conducted by Baykan Z., et al. [5] where it was found to be (30.3\%). However the trimodality preference in both the studies is found to be consistent that is $18.3 \%$ in the present study and $20.7 \%$ in the study conducted by Baykan Z., et al. [5]. Further when quadmodal preference was taken into consideration, it was found to be higher (12.9\%) in the study conducted by Baykan Z., et al. [5] than in the present study. Such inconsistencies in the result can be attributed to the fact that present study recruited dental and allied health science students who have a busy and hectic schedule which refrains them from using a quadmodal learning style which can be time consuming.

Moreover, if the modality of the learning styles was classified into unimodal and multimodal, then in the present study $26.3 \%$ had preference for unimodal learning style which was lower than the findings of the study conducted by Peyman., et al. [3] where it was found to be (41.6\%). Furthermore, in the present study $73.7 \%$ preferred multimodal type of learning which was similar to the findings of the study conducted by Peyman., et al. [3] where it was found to be $58.4 \%$.

When the performance of the students was taken into consideration, in the present study no significant difference was found between the learning styles and academic performance, however significant difference was found between academic performance and the modality used in learning which was in contrast to the study done by Wong SY., et al. [6] where there was a significant difference between educational grades and majors and modal of VARK styles $(p=0.008)$. However, the mean VARK subscale scores did not differ significantly between high achievers and non-high achievers ( $p$ $>0.05$ ). Further, the findings of the present study were compliant with the study conducted by Liew SC., et al. [7] where it was found that the learning styles did not contribute significantly towards the learning outcomes $(\mathrm{p}>0.05)$.

The complex nature of dental as well as allied health science education underlines the importance of knowing what preferences might exist among the students-in-training, and what are the characteristics of their preferences. The knowledge of these preferences may potentially increase the efficiency of the education process. Educators should be aware of these differences in order to accommodate or at least explore the possibilities of improving opportunities for aural and kinesthetic learners. Academicians 
should also recognize that many students are engaged in a high level of self-directed learning, demonstrating a need for more interactive, electronic instructional media. The purpose of introducing the VARK survey is to provide a vehicle for self-knowledge and to explore opportunities for making the educational experience both more productive and enjoyable for students and faculty members

\section{Conclusion}

The present educational system focuses mainly on the ways in which students are being taught. The questionnaires of VARK are extensively used by researchers to analyse learning style preferences. It is essential for the teacher or the educator to recognise that students have different styles of learning. This recognition will aid them to consider selecting different modalities and preferences, and reflect on the instruction modes effectiveness.

The outcome of this research provides useful insights for enhancing the learning experiences for dental students through the use of the VARK inventory. For a more productive education and instruction/tutors need to widen their style and range of presentation to help build a more effective and positive environment of learning for all the students. Further, the educators should attempt to tailor their educational subject delivery to accommodate the $\mathrm{s}$ styles of their students, especially those with a unimodal style of learning. On the learner's side, students with a unimodal learning style preference should try multimodal learning styles if their past academic performance was less than ideal. Knowing the students have different preferred learning modes will help the instructors in the faculty develop appropriate learning approaches and explore opportunities so that they will be able to make the educational experience for the students more productive.

\section{Bibliography}

1. James S., et al. "Learning preferences of first year nursing and midwifery students: utilising VARK". Nurse Education Today 31 (2011): 417-423.

2. Fleming ND and Mills C. "Not another inventory: rather a catalyst for reflection". Professional and Organizational Development Network in Higher Education, editors. To improve the academy: resources for faculty, instructional and organizational development. Stillwater (OK): New Forums Press (1992): 137-155.
3. Peyman H., et al. "Using VARK Approach for Assessing Preferred Learning Styles of First Year Medical Sciences Students: A Survey". Iranian Journal of Clinical and Diagnostic Research 8.8 (2014): GC01-GC04.

4. Aldosari MA., et al. "Learning style preferences of dental students at a single institution in Riyadh, Saudi Arabia, evaluated using the VARK questionnaire". Advances in Medical Education and Practice 9 (2018): 179-186.

5. Baykan $\mathrm{Z}$ and $\mathrm{Nac}_{s}$ ar M. "Learning styles of first-year medical students attending Erciyes University in Kayseri, Turkey". Advances in Physiology Education 31 (2007): 158-160.

6. Paiboonsithiwong S., et al. "Learning styles, academic achievement, and mental health problems among medical students in Thailand". Journal of Educational Evaluation for Health Professions 31.13 (2016): 38.

7. Liew SC. "The relationship between learning preferences and learning outcomes among preclinical undergraduate medical students". BMC Medical Education 15.4 (2016): 1-8.

\section{Assets from publication with us}

- Prompt Acknowledgement after receiving the article

- Thorough Double blinded peer review

- Rapid Publication

- Issue of Publication Certificate

- High visibility of your Published work

Website: www.actascientific.com/

Submit Article: www.actascientific.com/submission.php

Email us: editor@actascientific.com

Contact us: +919182824667 